\title{
Impact of perioperative administration of $6 \%$ hydroxyethyl starch 130/0.4 on serum cystatin C-derived renal function after radical prostatectomy: a single-centre retrospective study
}

\author{
Stefan Südfeld ${ }^{1 *+}$, Sami R. Leyh-Bannurah ${ }^{2 \dagger}$, Lars Budäus², Markus Graefen², Philip C. Reese ${ }^{1}$,
} Franziska von Breunig ${ }^{1}$, Daniel A. Reuter ${ }^{1}$ and Bernd Saugel ${ }^{1}$

\begin{abstract}
Background: Hydroxyethyl starch (HES) is used for repletion of acute intravasal volume loss in surgical patients. However, in critically ill patients, HES is associated with acute kidney injury. We aimed to evaluate the effect of HES on perioperative cystatin C (cystC)-derived estimated glomerular filtration rates (eGFR $\mathrm{R}_{\text {cyst }}$ ) in patients undergoing open and robot-assisted radical prostatectomy.

Methods: In this retrospective study we included 179 patients who underwent general anaesthesia for radical prostatectomy, received HES perioperatively, and had complete cystC and fluid therapy data available. CystC and corresponding eGFR $\mathrm{Cystc}_{\mathrm{C}}$ at postoperative days 1, 3, and 5 were compared with preoperative baseline using Wilcoxon rank-sum test.
\end{abstract}

Results: In 179 eligible patients, 6 \% HES 130/0.4 was administered in a median (25th to 75th percentile) dose of $1000 \mathrm{~mL}$ (1000 to $1000 \mathrm{~mL}$ ). Baseline eGFR cystc was $109.4 \mathrm{~mL} / \mathrm{min}$ (100.3 to $118.7 \mathrm{~mL} / \mathrm{min}$ ). eGFR $\mathrm{R}_{\text {cystc }}$ on postoperative days 1,3 , and 5 was $120.4 \mathrm{~mL} / \mathrm{min}$ (109.4 to $134.0 \mathrm{~mL} / \mathrm{min}), 120.4 \mathrm{~mL} / \mathrm{min}$ (109.4 to $132.9 \mathrm{~mL} / \mathrm{min}$ ), and $117.9 \mathrm{~mL} / \mathrm{min}$ (106.6 to $129.8 \mathrm{~mL} / \mathrm{min}$ ), respectively ( $p<0.001$ compared with baseline, each). No patient had an eGFR cystc-decrease of $\geq 25 \%$ from baseline.

Conclusions: The results indicate that the administration of a median dose of $1000 \mathrm{~mL}$ of $6 \%$ HES 130/0.4 is not associated with a postoperative deterioration of renal function in patients with normal to near-normal baseline renal function undergoing radical prostatectomy.

Keywords: Acute kidney injury, Anesthesia, Kidney function tests, Perioperative period

\footnotetext{
* Correspondence: suedfeld.research@gmx.de

${ }^{\dagger}$ Equal contributors

'Department of Anesthesiology, Center of Anesthesiology and Intensive Care

Medicine, University Medical Center Hamburg-Eppendorf, Martinistrasse 52,

20246 Hamburg, Germany

Full list of author information is available at the end of the article
} 


\section{Background}

Postoperative acute kidney injury (AKI) is highly prevalent [1] and associated with increased hospital mortality [2]. Multiple factors contribute to AKI, e.g. the type of surgery and haemodynamic instability [3]. Moreover, recent studies suggested that the administration of fluids containing hydroxyethyl starch (HES) leads to a moderately increased risk of AKI and increased requirement of renal replacement therapy in critically ill patients [4-6]. In the operative setting, on the contrary, this connection is currently not clearly evident [7]. In patients undergoing major surgery, prospective studies did not show a considerable effect of perioperatively administered HES on estimated glomerular filtration rate (eGFR) calculated based on serum creatinine $(\mathrm{sCr})$ [8-10].

Similar results were obtained when using the more sensitive $[11,12]$ glomerular filtration rate (GFR)-marker cystatin C (cystC) [13, 14]. Therefore, a possible contextdependency (i.e. elective surgery vs. critical illness) of the degree of apparent adverse effects of HES on kidney function may exist.

We hypothesised that perioperative administration of HES for the replacement of acute intravasal volume loss due to intraoperative haemorrhage does not lead to clinically relevant impairment of eGFR in a population of elective surgical patients without marked a priori risk of AKI. This in itself would be an important finding for a more detailed understanding of differential indications and contraindications of HES.

Therefore, we evaluated the influence of perioperatively administered HES on eGFR determined by sequential cystC measurements $\left(\mathrm{eGFR}_{\text {cystC }}\right)$ in a general patient population undergoing open radical prostatectomy (ORP) or robot-assisted radical prostatectomy (RARP) in a specialised prostate cancer centre at a large university hospital.

\section{Methods}

\section{Study design}

The study protocol of this retrospective analysis (ethics committee number PV4998) was reviewed and approved by the appropriate ethics committee (Ethikkommission der Ärztekammer Hamburg, Hamburg, Germany). Due to the retrospective nature of the study and the anonymisation of data the need for informed consent was waived by the ethics committee.

To evaluate the influence of perioperatively administered HES on eGFR $_{\text {cystC }}$ in patients undergoing ORP or RARP, we retrospectively extracted and analysed data from the hospital-wide digital patient record system that included biometric, medical, procedural, and physiologic parameters of patients in whom perioperative cystC measurements had been performed during their hospitalisation for ORP or RARP between September 2012 and April 2013.

\section{Patients; inclusion/exclusion criteria}

Patients were eligible for study inclusion if they a) had undergone general anaesthesia for ORP or RARP (without the need for a re-intervention within 5 days from the original operation), b) had received HES perioperatively, c) had cystC measurements recorded in their electronic hospital charts (at least one cyst $C$ value measured preoperatively (baseline) and at least one cystC value measured on days 1 or 3 ), and d) had complete documentation of perioperative fluid therapy in the digital patient record system.

\section{Data acquisition}

We extracted data on the type of radical prostatectomy (ORP vs. RARP), duration of surgery, intraperitoneal pressure (in RARP), and estimated intraoperative blood loss from surgical records. Biometric and medical status data, including relevant pre-existing co-morbidities and longterm medication, were obtained from preoperative anaesthesiological evaluation notes. For the operative period (including post anaesthesia care unit), we extracted data from the corresponding anaesthesia records. Laboratory data were extracted from the digital patient record system for preoperative baseline and days 1, 3, and 5. Baseline systolic arterial blood pressure (SAP) was defined as the first SAP measurement at the time of the patients' arrival in the anaesthesia induction area. Doses of norepinephrine were expressed as the maximum infusion rate during the time under anaesthetic care. For perioperative fluid and volume therapy, the colloid $6 \%$ HES 130/0.4 (Vololyte; Fresenius Kabi Deutschland GmbH, Bad Homburg, Germany) and the balanced full electrolyte solution (Sterofundin $^{\circledR}$; B. Braun Melsungen AG, Melsungen, Germany) were used. The documented units of intravenous fluids (i.e. crystalloids, colloids, or blood products) were assumed to be administered completely without residue.

\section{Calculation of estimated glomerular filtration rate from serum cystatin $\mathrm{C}$}

For the calculation of $\mathrm{GFR}_{\text {cystC, }}$, we used the formula previously published by Le Bricon and colleagues: [15].

$\operatorname{eGFR}_{\text {cystC }}(\mathrm{mL} / \mathrm{min})=78 \times$ cystC $[\mathrm{mg} / \mathrm{L}]^{-1}+4$.

For eGFR derived from concomitant $\mathrm{sCr}$ measurements $\left(\mathrm{eGFR}_{\text {crea }}\right)$, we applied the simplified Modification of Diet in Renal Disease (MDRD-4)-formula: [16].

$\mathrm{eGFR}_{\text {crea }}(\mathrm{mL} / \mathrm{min})=186 \times \mathrm{sCr}[\mathrm{mg} / \mathrm{dL}]^{-1,154} \times$ age $[\mathrm{yrs}]^{-}$

0,203 , corrected for sex and race $(\times 1$, if male Caucasian). If not stated in the patient records, the patient's race was assumed to be Caucasian. All eGFR $_{\mathrm{x}}$-values stated in this publication are normalised for $1.73 \mathrm{~m}^{2}$ body surface area.

\section{Statistical analysis}

We present descriptive statistical analyses as median (25th to 75 th percentile range) for continuous data and 
as absolute frequencies with percentages for categorical data. Within-group differences were evaluated using Wilcoxon rank-sum test for paired non-parametric data. Box-whisker-plots were created for illustration of chosen non-parametric data. For data management we used Microsoft Excel 2010 (Microsoft Corp., Redmond, WA, USA) and for statistical analyses and figures we used IBM SPSS Statistics, Version 21.0 (IBM Corp., Armonk, NY, USA).

Cases, in which data were missing, were excluded in the respective analysis. Statistical significance was assumed for $p<0.05$.

\section{Results}

\section{Patients}

In this study we analysed 179 patients (Fig. 1). Of note, 8 Patients were excluded a priori who did not receive HES perioperatively. We present the patients' characteristics in Table 1.

\section{Procedural data}

Procedural data of the study population, including haemodynamic therapy, are presented in Table 2.
The median dose of administered HES was $1000 \mathrm{~mL}$ $(1000$ to $1000 \mathrm{~mL})$. All patients additionally received crystalloid solution with a median dose of $3500 \mathrm{~mL}$ (2500 to $3500 \mathrm{~mL}$ ).

\section{Renal function}

We show data on baseline renal function and renal function on postoperative days 1,3 , and 5 in Table 3 and Figs. 2a, b, 3a, and b. Postoperative cystC values were available for 1,2 , and 3 postoperative days in $12(6.7 \%)$, 53 (29.6\%), and 114 (63.7 \%) patients, respectively.

The number of patients with increases in cystC and decreases in eGFR cystC $_{\text {of }} \geq 5 \%$ and of $\geq 10 \%$ on either of the postoperative days 1,3 , or 5 , compared with the preoperative baseline values were $21(11.7 \%)$ and $9(5.0 \%)$ patients, respectively, and $20(11.2 \%)$ and 7 (3.9\%) patients, respectively. No patient had a preoperative baseline eGFR cystC value below $60 \mathrm{~mL} / \mathrm{min}$. Of note, there was no patient with an increase in cystC or decrease in $\mathrm{GFR}_{\text {cystC }}$ of $\geq 25 \%$.

Compared with the median baseline values there was a statistically significant decrease in median cystC values and a statistically significant increase in median eGFR cystC values on postoperative day 1,3 , and 5 ( $p<0.001$, each).

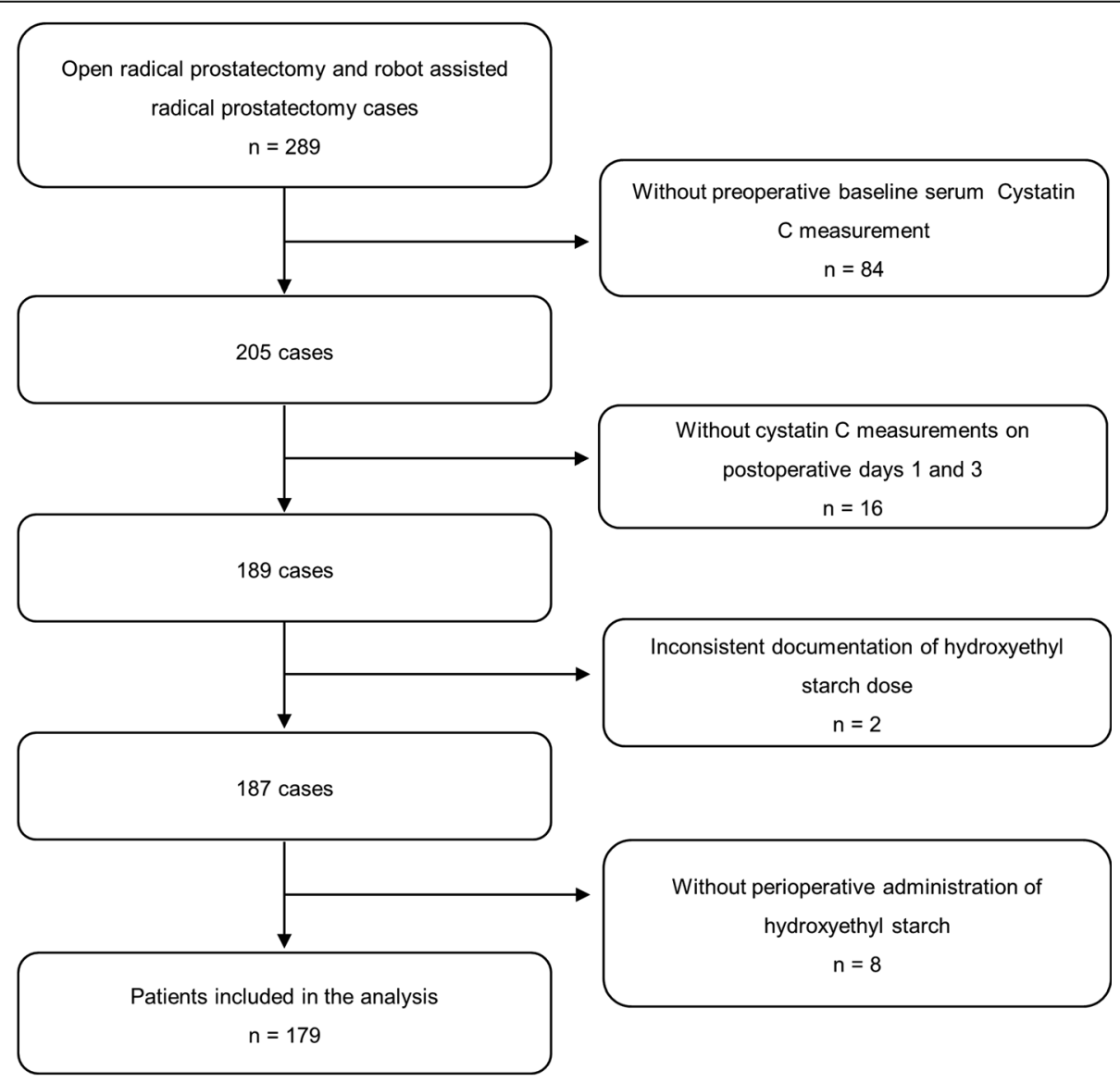

Fig. 1 Patient flow diagram. Illustration of patient exclusion 
Table 1 Patient characteristics

\begin{tabular}{|c|c|}
\hline Parameter, unit & Value \\
\hline Age, yrs & 64 (59 to 69) \\
\hline Weight, kg & 83.0 (76.0 to 90.0$)$ \\
\hline Height, m & $1.8(1.75$ to 1.83$)$ \\
\hline \multicolumn{2}{|l|}{ ASA physical status classification } \\
\hline । & $12(6.7)$ \\
\hline$\|$ & $115(64.2)$ \\
\hline III & $43(24.0)$ \\
\hline IV & $1(0.6)$ \\
\hline V & $0(0.0)$ \\
\hline $\mathrm{Vl}$ & $0(0.0)$ \\
\hline \multicolumn{2}{|l|}{ Medical co-morbidities } \\
\hline Chronic arterial hypertension & $80(44.7)$ \\
\hline Chronic heart failure & $1(0.6)$ \\
\hline Coronary artery disease & $7(3.9)$ \\
\hline Cerebrovascular disease & $11(6.1)$ \\
\hline Periphery artery disease & $1(0.6)$ \\
\hline Atrial fibrillation & $6(3.4)$ \\
\hline Chronic kidney disease & $1(0.6)$ \\
\hline Diabetes mellitus & $14(7.8)$ \\
\hline Rheumatoid arthritis & $2(1.1)$ \\
\hline \multicolumn{2}{|l|}{ Long-term Medication } \\
\hline Diuretic (thiazide, indapamid) & $17(9.5)$ \\
\hline Diuretic ( $\mathrm{K}^{+}$-sparing) & $2(1.2)$ \\
\hline Diuretic (loop of Henle) & $0(0.0)$ \\
\hline ACE-inhibitor & $26(14.5)$ \\
\hline AT1-blocker & $41(22.9)$ \\
\hline Renin-antagonist & $1(0.6)$ \\
\hline$\beta$-blocker & $29(16.2)$ \\
\hline Calcium channel-blocker & $22(12.3)$ \\
\hline$a_{1}$-blocker & $20(11.2)$ \\
\hline$a_{2}$-agonist & $3(1.7)$ \\
\hline NSAID & 25 (13.9) \\
\hline
\end{tabular}

Data presented as median (25th to 75th percentile) or number of cases (\%) ASA American Society of Anesthesiologists, ACE angiotensin-convertingenzyme, $A T 1$ angiotensin-receptor-1, NSAID non-steroidal anti-inflammatory drug

There was no statistically significant difference between median $\mathrm{sCr}$ and $\mathrm{eGFR}_{\text {crea }}$ values on postoperative days 1,3 , and 5 compared with baseline.

\section{Discussion}

The results of this retrospective analysis indicate that the administration of a median dose of $1000 \mathrm{ml} 6 \%$ HES $130 / 0.4$ is not associated with a postoperative deterioration of renal function in terms of a decrease in
Table 2 Procedural data

\begin{tabular}{|c|c|}
\hline Parameter, unit & Value \\
\hline \multicolumn{2}{|l|}{ Operation } \\
\hline Robot-assisted radical prostatectomy & $69(38.5)$ \\
\hline Open radical prostatectomy & $110(61.5)$ \\
\hline Duration of surgery, min & 190 (164 to 225$)$ \\
\hline Intraperitoneal pressure, if applicable, $\mathrm{mmHg}$ & 15 (15 to 15$)$ \\
\hline \multicolumn{2}{|l|}{ Mode of anaesthesia } \\
\hline Total intravenous & $86(48.0)$ \\
\hline Balanced & $93(52.0)$ \\
\hline Spinal (combined) & 72 (40.2) (all ORP) \\
\hline \multicolumn{2}{|l|}{ Haemodynamic data } \\
\hline Blood loss (intraoperative), mL & $500(250$ to 800$)$ \\
\hline Diuresis in PACU, $\mathrm{mL}$ & 800 (550 to 1200$)$ \\
\hline Pre-induction SAP, mmHg & $130(120$ to 140$)$ \\
\hline $\mathrm{SAP} \leq 100 \mathrm{mmHg}$ & $174(97.2)$ \\
\hline $\mathrm{SAP} \leq 90 \mathrm{mmHg}$ & $104(58.1)$ \\
\hline $\mathrm{SAP} \leq 80 \mathrm{mmHg}$ & $38(21.2)$ \\
\hline $\mathrm{SAP} \leq 70 \mathrm{mmHg}$ & $7(3.9)$ \\
\hline $\mathrm{SAP} \leq 60 \mathrm{mmHg}$ & $1(0.6)$ \\
\hline \multicolumn{2}{|l|}{ Haemodynamic therapy } \\
\hline HES solution, $\mathrm{mL}$ & 1000 (1000 to 1000$)$ \\
\hline Crystalloid solution, $\mathrm{mL}$ & $3500(2500$ to 3500$)$ \\
\hline Cases administered RCCs & $4(2.3)$ \\
\hline Number of RCCs, if administered & 2.0 (1.3 to 2.0$)$ \\
\hline Cases administered FFPs & $0(0.0)$ \\
\hline Cases administered PCs & $0(0.0)$ \\
\hline Maximum norepinephrine dose, $\mu \mathrm{g} / \mathrm{min}$ & $6.0(5.0$ to 9.0$)$ \\
\hline
\end{tabular}

Data presented as median (25th to 75 th percentile) or number of cases (\%) ORP open radical prostatectomy, PACU post anaesthesia care unit, SBP systolic arterial blood pressure, HES hydroxyethyl starch, $R C C$ red cell concentrate, FFP fresh frozen plasma, $P C$ platelet concentrate

eGFR $_{\text {cystC }}$ in patients with normal to near-normal baseline renal function undergoing radical prostatectomy.

Compared with sCr, CystC is a more accurate and precise estimator of a near-normal eGFR from 60 to $90 \mathrm{~mL} /$ $\min [17,18]$. It further exhibits a higher sensitivity for eGFR-changes $[11,12]$. Thus, it may detect postoperative AKI earlier as opposed to $\mathrm{sCr}$ [19], i.e. as early as one day postoperatively with peak values on day three [20]. Therefore, a possible increase in cystC due to surgery-related AKI should have likely been detected by cystC-measurements during the observed time span in this study.

There are some, mainly smaller clinical studies using cystC for the investigation of the effect of perioperative $6 \%$ HES 130/0.4 on renal function in individuals without acute systemic disease. In a randomised controlled trial (RCT), Mukhtar and colleagues tested $6 \%$ HES 
Table 3 Renal function

\begin{tabular}{|c|c|c|}
\hline Parameter, unit & $\begin{array}{l}\text { Number of patients } \\
\text { with available data, } \mathrm{n}\end{array}$ & Value \\
\hline Graded baseline eGFR $R_{\text {cyst }}, n$ & 179 & \\
\hline$\geq 90 \mathrm{~mL} / \mathrm{min}$ & & $157(87.7)$ \\
\hline $60-89 \mathrm{~mL} / \mathrm{min}$ & & $22(12.3)$ \\
\hline $30-59 \mathrm{~mL} / \mathrm{min}$ & & $0(0.0)$ \\
\hline $15-29 \mathrm{~mL} / \mathrm{min}$ & & $0(0.0)$ \\
\hline$<15 \mathrm{~mL} / \mathrm{min}$ & & $0(0.0)$ \\
\hline \multicolumn{3}{|l|}{ Serum cystatin C, mg/L } \\
\hline Preoperative baseline & 179 & 0.74 (0.68 to 0.81 ) \\
\hline Postoperative day 1 & 171 & $0.67(0.60 \text { to } 0.74)^{*}$ \\
\hline Postoperative day 3 & 157 & $0.67(0.61 \text { to } 0.74)^{*}$ \\
\hline Postoperative day 5 & 132 & $0.69(0.62 \text { to } 0.76)^{*}$ \\
\hline \multicolumn{3}{|l|}{ Serum creatinine, mg/dL } \\
\hline Preoperative baseline & 179 & 1.00 (0.80 to 1.10$)$ \\
\hline Postoperative day 1 & 178 & 0.90 (0.80 to 1.10$)$ \\
\hline Postoperative day 3 & 163 & 0.90 (0.80 to 1.00$)$ \\
\hline Postoperative day 5 & 136 & 0.90 (0.90 to 1.00$)$ \\
\hline \multicolumn{3}{|l|}{ eGFR $\mathrm{eyst}_{\text {ct }} \mathrm{mL} / \mathrm{min}$} \\
\hline Preoperative baseline & 179 & $109.4(100.3$ to 118.7$)$ \\
\hline Postoperative day 1 & 171 & $120.4(109.4 \text { to } 134.0)^{*}$ \\
\hline Postoperative day 3 & 157 & $120.4(109.4 \text { to } 132.9)^{*}$ \\
\hline Postoperative day 5 & 132 & $117.9(106.6 \text { to } 129.8)^{*}$ \\
\hline \multicolumn{3}{|l|}{ eGFR $\mathrm{Crea}_{\text {cr }} \mathrm{mL} / \mathrm{min}$} \\
\hline Preoperative baseline & 179 & 83.4 (72.1 to 100.4$)$ \\
\hline Postoperative day 1 & 178 & 88.3 (72.0 to 101.1$)$ \\
\hline Postoperative day 3 & 163 & 88.4 (77.9 to 102.5$)$ \\
\hline Postoperative day 5 & 136 & 88.0 (77.9 to 94.5$)$ \\
\hline
\end{tabular}

Graded eGFR cystC $=$ number of patients with preoperative baseline eGFR $\mathrm{cystC}_{\mathrm{c}}$ values within one of the listed ranges (no patient has a preoperative baseline eGFR $_{\text {cystC-Value below }} 60 \mathrm{~mL} / \mathrm{min}$; eGFR cystC $=$ serum cystatin C-derived and $\mathrm{eGFR}_{\text {crea }}=$ serum creatinine-derived glomerular filtration rate. All values are presented as median (25th to 75 th percentile)

$p<0.001$ vs. preoperative baseline

130/0.4 against human $5 \%$ albumin in 40 living donor liver transplant recipients and found no difference in the perioperative course of cystC as well as creatinine clearance [14]. Harten and colleagues analysed data from 29 patients undergoing emergency abdominal surgery in their pilot RCT to investigate the influence of goal directed haemodynamic therapy on kidney function using $6 \%$ HES 130/0.4 in the intervention group vs. usual care for the control-group, while the latter received unspecified colloids different than HES. In their study, there was no statistically significant difference in cystC or $\mathrm{sCr}$ between groups [21]. These findings as well as our own results provide some evidence that there are no harmful effects of HES on the GFR in surgical patients in the absence of critical illness.
These findings are in line with a study analysing kidney biomarkers other than cystC in 40 patients undergoing ORP randomised to receive either 6 \% HES 130/0.4 or $0.9 \%$ saline perioperatively [22]. In this study, there was no deleterious effect in the HES compared to the normal saline group with regard to $\mathrm{sCr}$, creatinine clearance, neutrophil gelatinase associated lipocalin, as well as the markers of the renin-angiotensin-aldosteronepathway [22].

A meta-analysis of 19 RCTs including studies on the influence of various $6 \%$ HES solutions on hospital mortality and AKI or renal replacement therapy in surgical patients revealed no statistically significant differences in outcomes in the patients receiving HES compared to the patients receiving the respective alternative solutions [7].

Our results show, that there is not only no increase in cystC levels from baseline values, but that there is even a decrease in cystC. We did not expect the corresponding eGFR $\mathrm{cystC}_{\text {to }}$ to increase in the context of major surgery, which is associated with blood loss and catecholamine use. To offer an explanation, a recent study with healthy volunteers showed that infusion of fluids, including $6 \%$ HES 130/0.4, even though net cystC serum content rises, leads to a dilution of serum cystC concentration early after the infusion [23]. However, as $6 \%$ HES 130/0.4 has a terminal half-life of $16.1 \mathrm{~h}$ independent of the degree of pre-existing renal impairment [24], in theory, postoperatively rather than intraoperatively infused fluids may have caused such an effect on cystC on day 3 or 5 postoperatively. Moreover, it has been shown that an increase in extracellular fluid volume leads to increased GFR above baseline values in patients without renal impairment, partly compensating for the extracellular fluid increase, as long as the patients do not exhibit increased extracellular volume at baseline due to fluid overload caused by pre-existing chronic kidney disease [25]. A relatively high ratio of administered fluid volume and blood loss in our patients may have led to this dilution effect. This may be interpreted as an acute compensatory increase in GFR in patients without kidney disease as well as falsely high postoperative eGFR $_{\text {cystC }}$ values as a result of a dilution effect on cystC serum concentration.

Risk factors for postoperative AKI have been identified for general surgical [3] as well as urological [26] patients. While urological surgery per se is frequently associated with AKI, the patient subgroup studied here is at no particularly increased risk.

Previous clinical trials have demonstrated adverse effects of HES on renal function and need for renal replacement therapy in patients with severe sepsis [4-6] which has led to the extension of the contraindications of HES for critically ill patients in general $[27,28]$. Moreover, concerns have been raised, that the use of HES in 


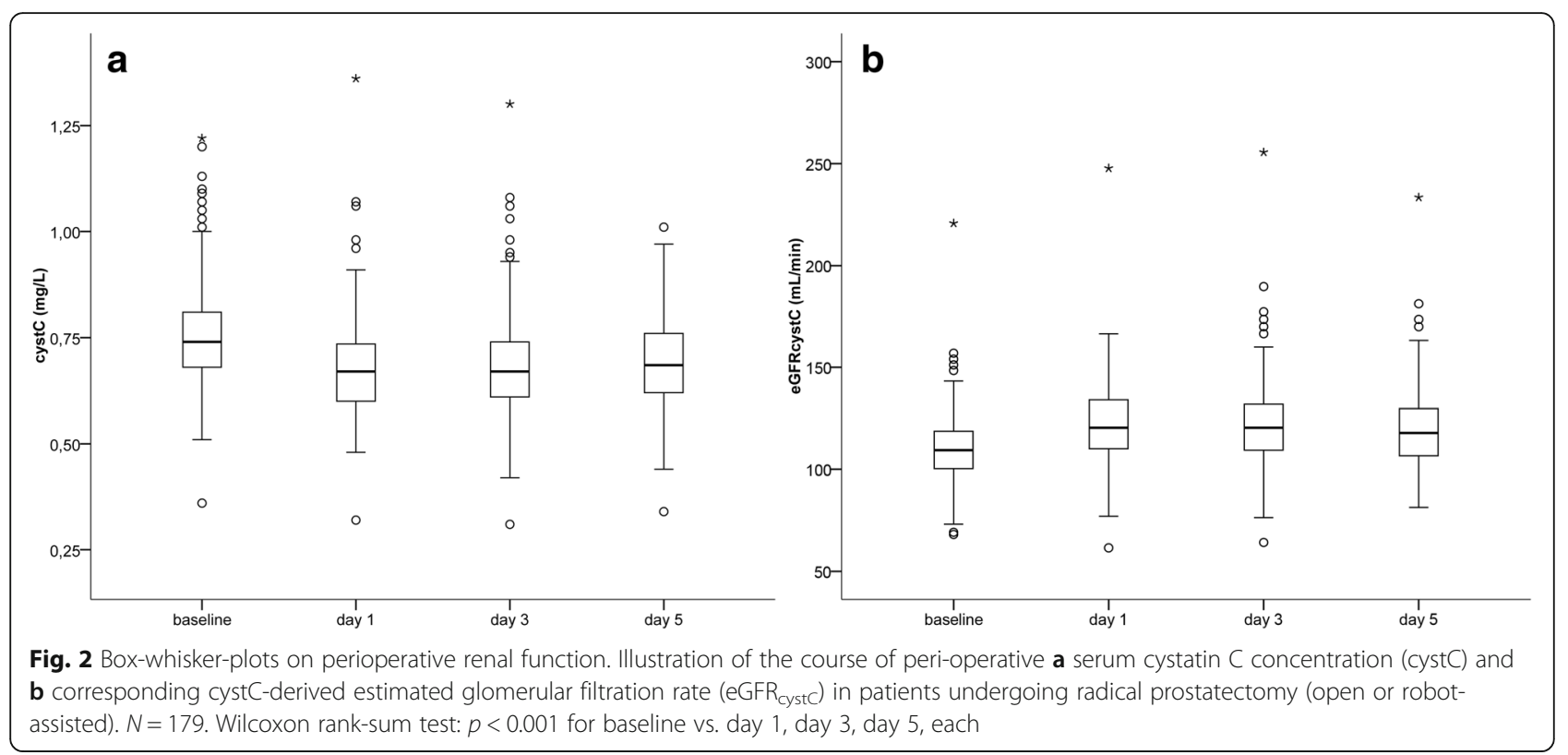

patients without severe systemic disease may be unsafe, as well [29], however, convincing evidence concerning this matter is still lacking. The main result of the current study, along with other studies, builds the hypothesis that there may be a differential effect of HES on GFR depending on the study population and the clinical context.

Our study has several limitations. The retrospective nature of the study is a major limitation of our study and might restrict generalisability of the results. In addition, we made the assumption that all bags of fluids and blood products were infused or transfused entirely.
In addition, it was assumed that all patients were of Caucasian ethnicity. None of the patients in this study exhibited a perioperative rise in cystC, where the corresponding fall in $\mathrm{eGFR}_{\text {cystC }}$ would be considered relevant for the diagnosis of AKI according to Risk, Injury, Failure, Loss, and End-stage kidney disease (RIFLE) classification criteria [30]. As a result, further analyses aiming at identifying possible influencing factors on perioperative AKI are inapplicable. This study solely focused on eGFR as a parameter of kidney function, while the novel set of structural biomarkers may be considered useful for future prospective studies [31]. Due to its
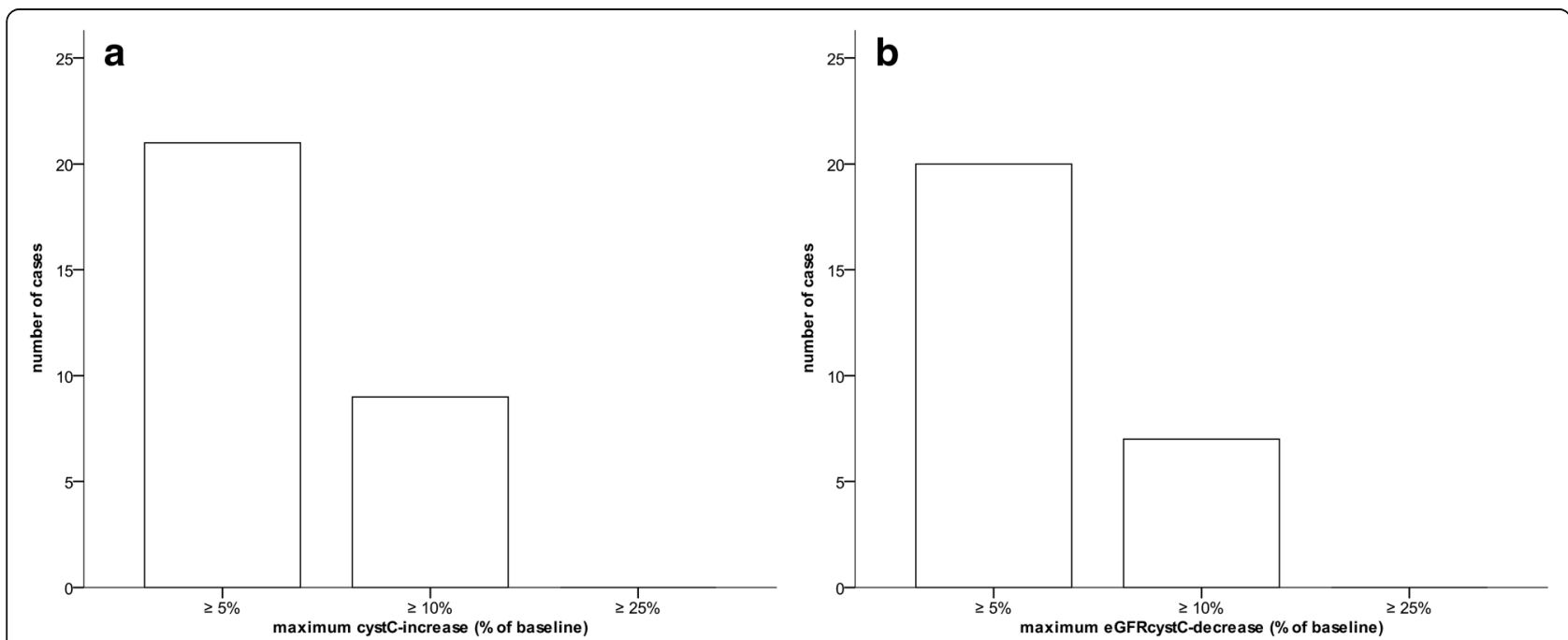

Fig. 3 Frequencies of perioperative renal function deterioration. Frequency of maximum perioperative a serum Cystatin C (cystC)-increase and b cystC-derived estimated glomerular filtration rate (eGFRcystC)-decrease in patients undergoing radical prostatectomy (open or robot-assisted) on postoperative days 1,3 or $5 . N=179$ 
retrospective design, it was not possible to exclude influencing factors on cystC other than the intraoperative fluid therapy. This study can neither make a statement on extra-renal side effects of HES in the study population (e.g. coagulopathy, oedema, cardiac decompensation or pruritus) nor on potential benefits from HES (e.g. haemodynamics, morbidity or mortality), as it was designed to test the hypothesis that HES does not exert harmful effects on kidney function, hence, no final conclusion on the risk/benefit-ratio of HES in this population can be given.

\section{Conclusions}

In conclusion, our study indicates that the administration of a median dose of $1000 \mathrm{~mL} 6$ \% HES 130/0.4 seems not to be associated with a clinically relevant perioperative deterioration of renal function in terms of a decrease in $\mathrm{GFFR}_{\text {cystC }}$ in patients with normal to nearnormal baseline renal function undergoing radical prostatectomy. As HES has continued to be in clinical use, large multicentre randomised controlled trials to confirm this notion seem warranted, in which sensitive markers of kidney function and structure should be used and potential benefits from HES should also be considered.

\begin{abstract}
Abbreviations
AKI: Acute kidney injury; cystC: Cystatin C; eGFR: Estimated glomerular filtration rate; GFR $_{\text {crea: }}$ Serum creatinine-derived estimated glomerular

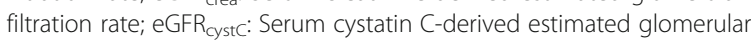
filtration rate; GFR: Glomerular filtration rate; HES: Hydroxyethyl starch; MDRD-4: Simplified Modification of Diet in Renal Disease; ORP: Open radical prostatectomy; RARP: Robot-assisted radical prostatectomy; RCT: Randomised controlled trial; RIFLE: Risk, Injury, Failure, Loss, and End-stage kidney disease; SAP: Systolic arterial blood pressure; sCr: Serum creatinine
\end{abstract}

\section{Acknowledgments}

Not applicable.

\section{Funding}

This work was supported by the Department of Anesthesiology, Center of Anesthesiology and Intensive Care Medicine, University Medical Center Hamburg-Eppendorf, Hamburg, Germany.

\section{Availability of data and materials}

The raw data supporting the findings will be shared upon request to the corresponding author.

\section{Authors' contributions}

SS: conceived and designed the study, was responsible for acquisition of data, performed the statistical analyses, was responsible for data analysis and interpretation, drafted the manuscript. SRL: was responsible for acquisition of data, performed the statistical analyses, was responsible for data analysis and interpretation, critically revised the manuscript for important intellectual content. LB: conceived and designed the study, was responsible for data analysis and interpretation, critically revised the manuscript for important intellectual content, supervised the study. MG: was responsible for data analysis and interpretation, critically revised the manuscript for important intellectual content. PCR: was responsible for acquisition of data, was responsible for data analysis and interpretation, critically revised the manuscript for important intellectual content. FB: was responsible for data analysis and interpretation, critically revised the manuscript for important intellectual content. DR: was responsible for data analysis and interpretation, critically revised the manuscript for important intellectual content. BS conceived and designed the study, was responsible for data analysis and interpretation, drafted the manuscript, supervised the study. All authors read and approved the final version of the manuscript and are agree to be accountable for all aspects of the work.

\section{Authors' information}

SS: Resident, Department of Anesthesiology, Center of Anesthesiology and Intensive Care Medicine, University Medical Center Hamburg-Eppendorf, Martinistrasse 52, 20246 Hamburg, Germany, suedfeld.research@gmx.de SRL: Resident, Martini Clinic, Prostate Cancer Center at University Medical Center Hamburg-Eppendorf, Martinistrasse 52, 20246 Hamburg, Germany, s.bannurah@googlemail.com

LB: Consultant, Martini Clinic, Prostate Cancer Center at University Medical Center Hamburg-Eppendorf, Martinistrasse 52, 20246 Hamburg, Germany, lars.budaeus@gmail.com

MG: Head consultant, Professor, Martini Clinic, Prostate Cancer Center at University Medical Center Hamburg-Eppendorf, Martinistrasse 52, 20246 Hamburg, Germany, graefen@uke.de

PCR: research assistant, Department of Anesthesiology, Center of Anesthesiology and Intensive Care Medicine, University Medical Center Hamburg-Eppendorf, Martinistrasse 52, 20246 Hamburg, Germany, reese.research@gmx.de

FVB: Consultant, Department of Anesthesiology, Center of Anesthesiology and Intensive Care Medicine, University Medical Center Hamburg-Eppendorf, Martinistrasse 52, 20246 Hamburg, Germany, f.breunig@uke.de

DAR: Head Consultant, Professor, Department of Anesthesiology, Center of Anesthesiology and Intensive Care Medicine, University Medical Center Hamburg-Eppendorf, Martinistrasse 52, 20246 Hamburg, Germany, dreuter@uke.de

BS: Internal medicine specialist, Resident, Department of Anesthesiology, Center of Anesthesiology and Intensive Care Medicine, University Medical Center Hamburg-Eppendorf, Martinistrasse 52, 20246 Hamburg, Germany, b.saugel@uke.de

\section{Competing interests}

The authors declare that they have no competing interests.

\section{Consent for publication}

There are no details, images or videos relating to individual participants included in this publication. Therefore, consent for publication was waived.

\section{Ethics approval and consent to participate}

The study protocol (ethics committee number PV4998) was reviewed and approved by the appropriate ethics committee (Ethikkommission der Ärztekammer Hamburg, Hamburg, Germany). Due to the retrospective nature of the study and the anonymisation of data the need for informed consent was waived by the ethics committee.

\section{Author details}

'Department of Anesthesiology, Center of Anesthesiology and Intensive Care Medicine, University Medical Center Hamburg-Eppendorf, Martinistrasse 52, 20246 Hamburg, Germany. ${ }^{2}$ Martini Clinic, Prostate Cancer Center at University Medical Center Hamburg-Eppendorf, Martinistrasse 52, 20246 Hamburg, Germany.

Received: 28 March 2016 Accepted: 24 August 2016

Published online: 30 August 2016

References

1. Wang HE, Muntner P, Chertow GM, Warnock DG. Acute kidney injury and mortality in hospitalized patients. Am J Nephrol. 2012;35:349-55.

2. Romagnoli S, Ricci Z. Postoperative acute kidney injury. Minerva Anestesiol. 2015;81:684-96.

3. Borthwick $E$, Ferguson A. Perioperative acute kidney injury: risk factors, recognition, management, and outcomes. BMJ. 2010;341:c3365.

4. Brunkhorst FM, Engel C, Bloos F, Meier-Hellmann A, Ragaller M, Weiler N, et al. Intensive insulin therapy and pentastarch resuscitation in severe sepsis. N Engl J Med. 2008;358:125-39. 
5. Myburgh JA, Finfer S, Bellomo R, Billot L, Cass A, Gattas D, et al. Hydroxyethyl starch or saline for fluid resuscitation in intensive care. N Engl J Med. 2012;367:1901-11.

6. Perner A, Haase N, Guttormsen AB, Tenhunen J, Klemenzson G, Åneman A et al. Hydroxyethyl starch 130/0.42 versus Ringer's acetate in severe sepsis. N Engl J Med. 2012;367:124-34

7. Gillies MA, Habicher M, Jhanji S, Sander M, Mythen M, Hamilton M, et al. Incidence of postoperative death and acute kidney injury associated with i. v. $6 \%$ hydroxyethyl starch use: systematic review and meta-analysis. $\mathrm{Br} \mathrm{J}$ Anaesth. 2014;112:25-34.

8. Godet G, Lehot J-J, Janvier G, Steib A, Castro V, Coriat P. Safety of HES 130/ 0.4 (Voluven(R)) in patients with preoperative renal dysfunction undergoing abdominal aortic surgery: a prospective, randomized, controlled, parallelgroup multicentre trial. Eur J Anaesthesiol. 2008;25:986-94.

9. Mahmood A, Gosling P, Vohra RK. Randomized clinical trial comparing the effects on renal function of hydroxyethyl starch or gelatine during aortic aneurysm surgery. Br J Surg. 2007;94:427-33.

10. Winkelmayer WC, Glynn RJ, Levin R, Avorn J. Hydroxyethyl starch and change in renal function in patients undergoing coronary artery bypass graft surgery. Kidney Int. 2003;64:1046-9.

11. Herget-Rosenthal S. Can serial measurements of cystatin C accurately detect early renal function decline? Nat Clin Pract Nephrol. 2005;1:68-9.

12. Newman DJ, Thakkar H, Edwards RG, Wilkie M, White T, Grubb AO, et al. Serum cystatin $C$ measured by automated immunoassay: a more sensitive marker of changes in GFR than serum creatinine. Kidney Int. 1995;47:312-8.

13. Lomivorotov W, Fominskiy EV, Efremov SM, Nepomniashchikh VA, Lomivorotov VN, Chernyavskiy AM, et al. Infusion of $7.2 \% \mathrm{NaCl} / 6 \%$ hydroxyethyl starch 200/0.5 in on-pump coronary artery bypass surgery patients: a randomized, single-blind pilot study. Shock. 2014;41:193-9.

14. Mukhtar A, Aboulfetouh F, Obayah G, Salah M, Emam M, Khater Y, et al. The safety of modern hydroxyethyl starch in living donor liver transplantation: a comparison with human albumin. Anesth Analg. 2009:109:924-30.

15. Le Bricon T, Thervet E, Froissart M, Benlakehal M, Bousquet B, Legendre C, et al. Plasma cystatin $C$ is superior to $24-h$ creatinine clearance and plasma creatinine for estimation of glomerular filtration rate 3 months after kidney transplantation. Clin Chem. 2000;46:1206-7.

16. Lameire N, Adam A, Becker CR, Davidson C, McCullough PA, Stacul F, et al. Baseline renal function screening. Am J Cardiol. 2006;98(6A):21K-6.

17. Herget-Rosenthal S, Bokenkamp A, Hofmann W. How to estimate GFRserum creatinine, serum cystatin C or equations? Clin Biochem. 2007:40: 153-61.

18. White C, Akbari A, Hussain N, Dinh L, Filler G, Lepage N, et al. Estimating glomerular filtration rate in kidney transplantation: a comparison between serum creatinine and cystatin C-based methods. J Am Soc Nephrol. 2005;16: 3763-70.

19. Herget-Rosenthal S, Pietruck F, Volbracht L, Philipp T, Kribben A. Serum cystatin C-a superior marker of rapidly reduced glomerular filtration after uninephrectomy in kidney donors compared to creatinine. Clin Nephrol. 2005;64:41-6.

20. Ristikankare A, Pöyhiä R, Kuitunen A, Skrifvars M, Hämmäinen P, Salmenperä $M$, et al. Serum cystatin $C$ in elderly cardiac surgery patients. Ann Thorac Surg. 2010;89:689-94.

21. Harten J, Crozier JE, McCreath B, Hay A, McMillan DC, McArdle CS, et al. Effect of intraoperative fluid optimisation on renal function in patients undergoing emergency abdominal surgery: a randomised controlled pilot study (ISRCTN 11799696). Int J Surg. 2008;6:197-204.

22. Kancir AS, Johansen JK, Ekeloef NP, Pedersen EB. The effect of $6 \%$ hydroxyethyl starch 130/0.4 on renal function, arterial blood pressure, and vasoactive hormones during radical prostatectomy: a randomized controlled trial. Anesth Analg. 2015;120:608-18.

23. Zdolsek JH, Bergek C, Lindahl TL, Hahn RG. Colloid osmotic pressure and extravasation of plasma proteins following infusion of Ringer's acetate and hydroxyethyl starch 130/0.4. Acta Anaesthesiol Scand. 2015; in press.

24. Jungheinrich C, Scharpf R, Wargenau M, Bepperling F, Baron JF. The pharmacokinetics and tolerability of an intravenous infusion of the new hydroxyethyl starch 130/0.4 (6\%,500 mL) in mild-to-severe renal impairment. Anesth Analg. 2002;95:544-51.

25. Bird NJ, Peters C, Michell AR, Peters AM. Association between glomerula filtration rate and extracellular fluid volume in normal subjects and patients with renal impairment. Scand J Clin Lab Invest. 2008:68:39-49.
26. Caddeo G, Williams ST, Mclntyre CW, Selby NM. Acute kidney injury in urology patients: incidence, causes and outcomes. Nephrourol Mon. 2013;5: 955-61.

27. European Medicines Agency (EMA). Hydroxyethyl-starch solutions (HES) no longer to be used in patients with sepsis or burn injuries or in critically ill patients. HES will be available in restricted patient populations. 2013. Available from http://www.ema.europa.eu/docs/en_GB/document_library/ Referrals_document/Solutions_for_infusion_containing_hydroxyethyl_ starch/European_Commission_final_decision/WC500162361.pdf. (Accessed 08 Jan 2016)

28. Food and Drug Administration. FDA Safety Communication: Boxed Warning on increased mortality and severe renal injury, and additional warning on risk of bleeding, for use of hydroxyethyl starch solutions in some settings. 2013. Available from http://www.fda.gov/BiologicsBloodVaccines/ SafetyAvailability/ucm358271.htm. (Accessed 08 Jan 2016)

29. Bion J, Bellomo R, Myburgh J, Perner A, Reinhart K, Finfer S. Hydroxyethyl starch: putting patient safety first. Intensive Care Med. 2014;40:256-9.

30. Bellomo R, Ronco C, Kellum J, Mehta R, Palevsky P, Acute Dialysis Quality Initiative workgroup. Acute renal failure - definition, outcome measures, animal models, fluid therapy and information technology needs: the Second International Consensus Conference of the Acute Dialysis Quality Initiative (ADQI) Group. Crit Care. 2004;8:R204-12.

31. Vanmassenhove J, Vanholder R, Nagler E, Van Biesen W. Urinary and serum biomarkers for the diagnosis of acute kidney injury: an in-depth review of the literature. Nephrol Dial Transplant. 2013;28:254-73.

\section{Submit your next manuscript to BioMed Central and we will help you at every step:}

- We accept pre-submission inquiries

- Our selector tool helps you to find the most relevant journal

- We provide round the clock customer support

- Convenient online submission

- Thorough peer review

- Inclusion in PubMed and all major indexing services

- Maximum visibility for your research

Submit your manuscript at www.biomedcentral.com/submit

Biomed Central 